TAO, Vol. 13, No. 3, 313-324, September 2002

\title{
Near Real-Time Seismic Damage Assessment of the Rapid Reporting System
}

\author{
Yih-Min Wu ${ }^{1, *}$, Nai-Chi Hsiao ${ }^{1}$, Ta-Liang Teng ${ }^{2}$, and Tzay-Chyn Shin ${ }^{1}$
}

(Manuscript received 1 March 2002, in final form 8 July 2002)

\begin{abstract}
Having the ability of near real-time damage assessment would benefit earthquake emergency response operations in Taiwan greatly. Thus, we established an empirical method of assessing the near real-time damage using the rapid reporting system in Taiwan. Relationships between peak ground velocity and damage rates (fatality rate, total and partial household collapsing rates) during the 1999 Chi-Chi earthquake were determined in this study. The distribution of the peak ground velocity can be mapped within minutes of post-initiation of a strong earthquake by the rapid reporting system of the Taiwan Central Weather Bureau (Wu et al. 2001). By correlating peak ground velocity with damage rates gathered by the rapid reporting system, a near real-time damage assessment can be issued, in addition to the epicenter, magnitude and intensity.
\end{abstract}

(Key words: Seismic damage rate, Seismic rapid reporting system, Peak ground acceleration, Peak ground velocity)

\section{INTRODUCTION}

Located on the westem circum-Pacific seismic belt with a plate convergence rate of $8 \mathrm{~cm} /$ year (Yu et al. 1999), Taiwan had experienced numerous destructive earthquakes with severe casualties and property losses. The potential earthquake hazard will continue to increase along with the population growth. Therefore, it is essential for Taiwan to seek means through scientific research to reduce future earthquake hazards.

Taiwan established several research programs actively pursing on earthquake rapid reporting system. A Taiwan Rapid Earthquake Information Release System (TREIRS) using a real-time strong-motion accelerograph network consisting 82 stations distributed around Taiwan were established by the Central Weather Bureau (CWB) (Fig. 1). Recent findings had

\footnotetext{
${ }^{1}$ Central Weather Bureau, Taipei, Taiwan, ROC

${ }^{2}$ Southern California Earthquake Center, University of Southern California, Los Angeles, California, USA

${ }^{*}$ Corresponding author address: Dr: Yih-Min Wu, Central Weather Bureau, 64 Kung-Yuan Road, Taipei, Taiwan ROC; E-mail: Iudan@ss2.cwb.gov.tw
} 
shown that the rapid reporting system (RRS) is becoming a promising tool for providing reliable and critical information during an earthquake emergency, and crucial in mitigating seismic hazards (United States Geological Survey, 1998). Recent developments of the RRS of the CWB have advanced the system (Teng et al. 1997; Wu et al. 1997, 1998, 1999, 2000, 2001). Currently, the system is capable of routine broadcasting of the earthquake location and its magnitude about one minute after the occurrence, achieving the early warning capacity ( $\mathrm{Wu}$ and Teng, 2002). The distributions of peak ground acceleration (PGA) and peak ground velocity (PGV) can also be mapped within two minutes. Thus, if empirical relationships between PGA, PGV and earthquake losses can be found, we can further the capability of near real-time damage assessment by CWB TREIRS in Taiwan.

The 1999 Chi-Chi earthquake not only caused big impact in the central Taiwan area, but also caused collapsing of high-rised buildings with large casualties in the Taipei basin, which is about $150 \mathrm{~km}$ away from the epicenter. The CWB collected high quality data of the strong ground motion during this earthquake, and provide an excellent opportunity to derive empirical relationships between PGA, PGV and earthquake losses with statistic evaluation by the National office of Statistics. Tsai et al. (2001) conducted the preliminary study on the relationship between peak ground motion and earthquake losses of the Chi-Chi earthquake, and pointed out positive correlation that high ground accelerations ( $>400 \mathrm{gal}$ ) associated in high fatality

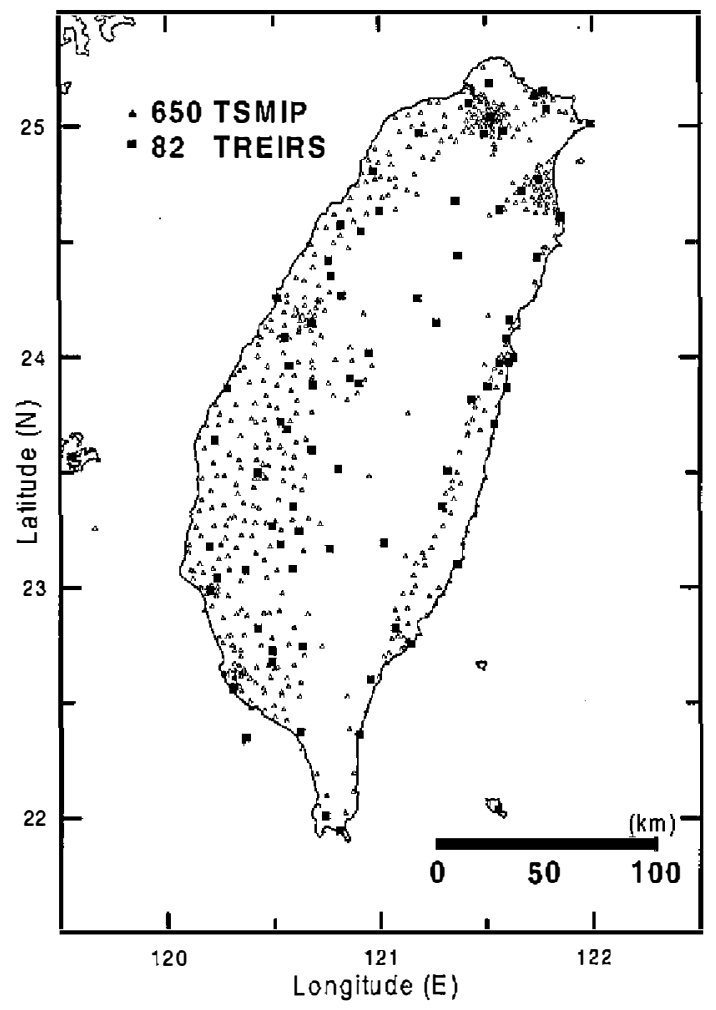

Fig. 1. Distribution of the 82 TREIRS stations and the 650 TSMIP stations. 
rates (a rapid increase of $1.112 \%$ of the involved population). Yet the amount of total and partial collapsed households remained about equal. Therefore, the relationships between PGA, PGV and earthquake damages still need further determination. In this study, we attempt to use all these data to evaluate the relationships between PGA, PGV and earthquake damage in Taiwan.

\section{DATA}

The Taiwan Strong Motion Instrumentation Program (TSMIP) implemented by the CWB years prior to the 1999 Chi-Chi earthquake has about 650 modern digital accelerographs installed at free-field sites (Fig. 1). In metropolitan areas the TSMIP inter-station spacing is about $5 \mathrm{~km}$. Most acceleration sensor recording ranges are $\pm 2 \mathrm{~g}$. It offers detailed description of ground shaking and damage assessment. The TSMIP signals are digitized at 200 samples per second or higher and at 16-bit or higher. Over 30,000 digital strong-motion records were obtained from the Chi-Chi earthquake and thousands for the aftershocks. The TSMIP recorded strong-motion by 441 stations for the mainshock (Lee et al. 2001), which is the largest data set of strong-motion from a major earthquake since begging of strong-motion recording in the 1930s. This data set is important to seismology as well as to earthquake engineering because it includes over 60 recording sites within $20 \mathrm{~km}$ of fault ruptures, providing a five-fold increase of near source strong-motion records from major earthquakes of the world. These mainshock strong-motion records were utilized to calculate for PGA and PGV values of individual townships in Taiwan.

The National Office of Statistics (2001) separated the 1999 Chi-Chi earthquake damages into three categories: fatalities, total-collapsed households and partial-collapsed households in individual townships. Each household represents the officially registered residence unit, and averagely there are 3.3 persons per household in Taiwan. We used households instead of the number of the buildings in this study because:

(1) The data were well collected and provided for the National Office of Statistics.

(2) Number of the households is a better index than the number of buildings, since a high-rised building may contain several tens to hundreds households, and a low-rised building may contain one or two households.

\section{ANALYSIS AND RESULTS}

We applied five parameters of PGA, PGV, fatality rate, total and partial collapsed household rates in individual townships, where PGA and PGV values were determined from TSMIP strong-motion records of the 1999 Chi-Chi earthquake. The fatality rate, total and partial collapsed household rates in individual townships were carefully determined during the disaster relief operations according to the population records of the 1999 demographic summary (National Office of Statistics, 2000). Figure 2 shows the townships boundary and their geometrical centers in Taiwan. Figure 3 shows the total-collapsed household rate in every township along the distribution of PGA in central and northern Taiwan. Apparently, large house- 


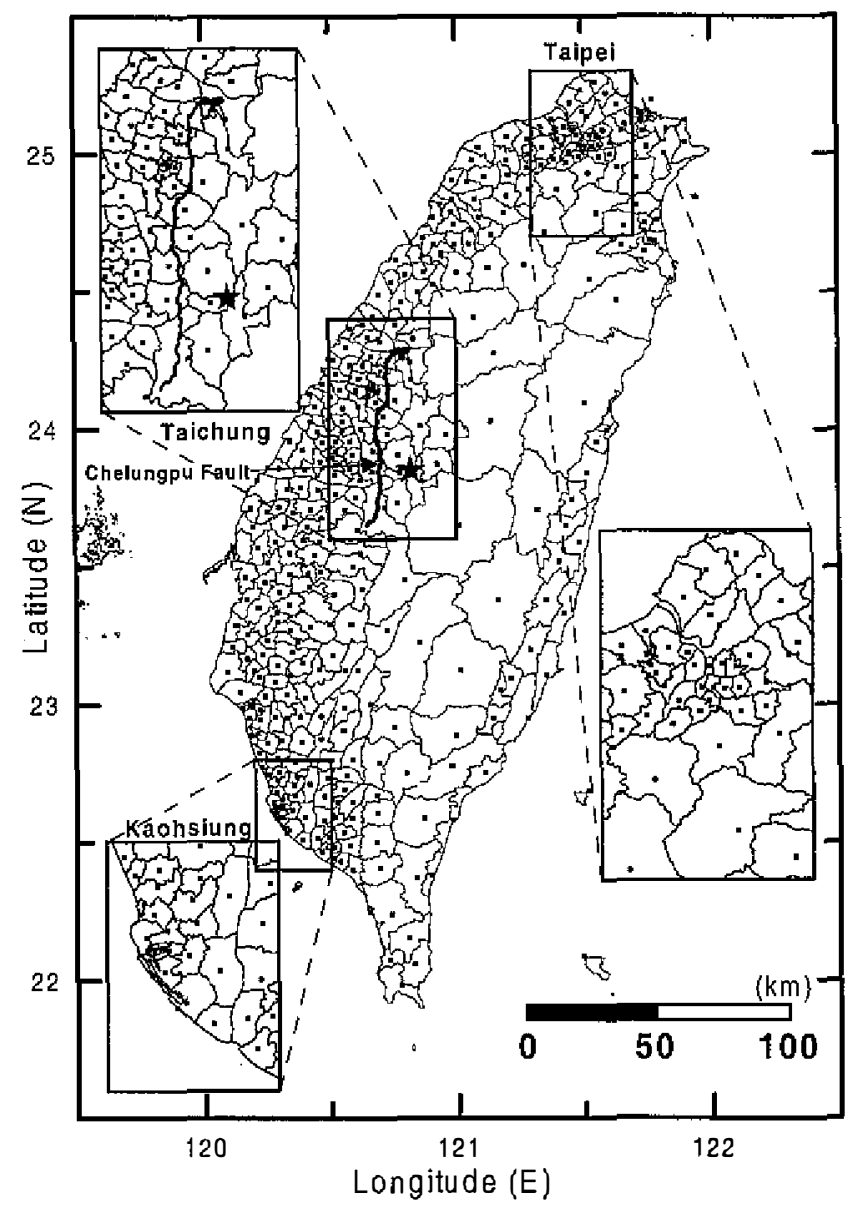

Fig. 2. Distribution of the townships boundary and their geometrical centers (solid squares) in Taiwan region.

hold collapse rates occurred in the townships with high PGA (>400 gal), and mostly distributed on the hanging wall of the Chelungpu fault (east side). Both PGA and household collapse rates decreased sharply to the foot wall (west side) of the Chelungpu fault. Figure 4 shows the distribution of fatality rates and PGV values for every township in central and northern Taiwan. All fatalities took place in the townships with PGV values greater than $20 \mathrm{~cm} / \mathrm{sec}$, and the fatality rates greatly increased when PGV reached $60 \mathrm{~cm} / \mathrm{sec}$ and higher.

For regression analysis, we applied Kriging method to calculate the PGA and PGV values of the geometrical center of each township with assigned average PGA and PGV values. Table 1 and Table 2 show the averaged damage rates within different PGA and PGV ranges for regression analysis.

Logarithm regression of the damage rate with PGA and PGV values yielded roughly linear relation. Figures 5 and 6 illustrate the regression relations of the observed and predicted damage rates (dots) with PGA and PGV values (solid lines), as the regressions were defined 

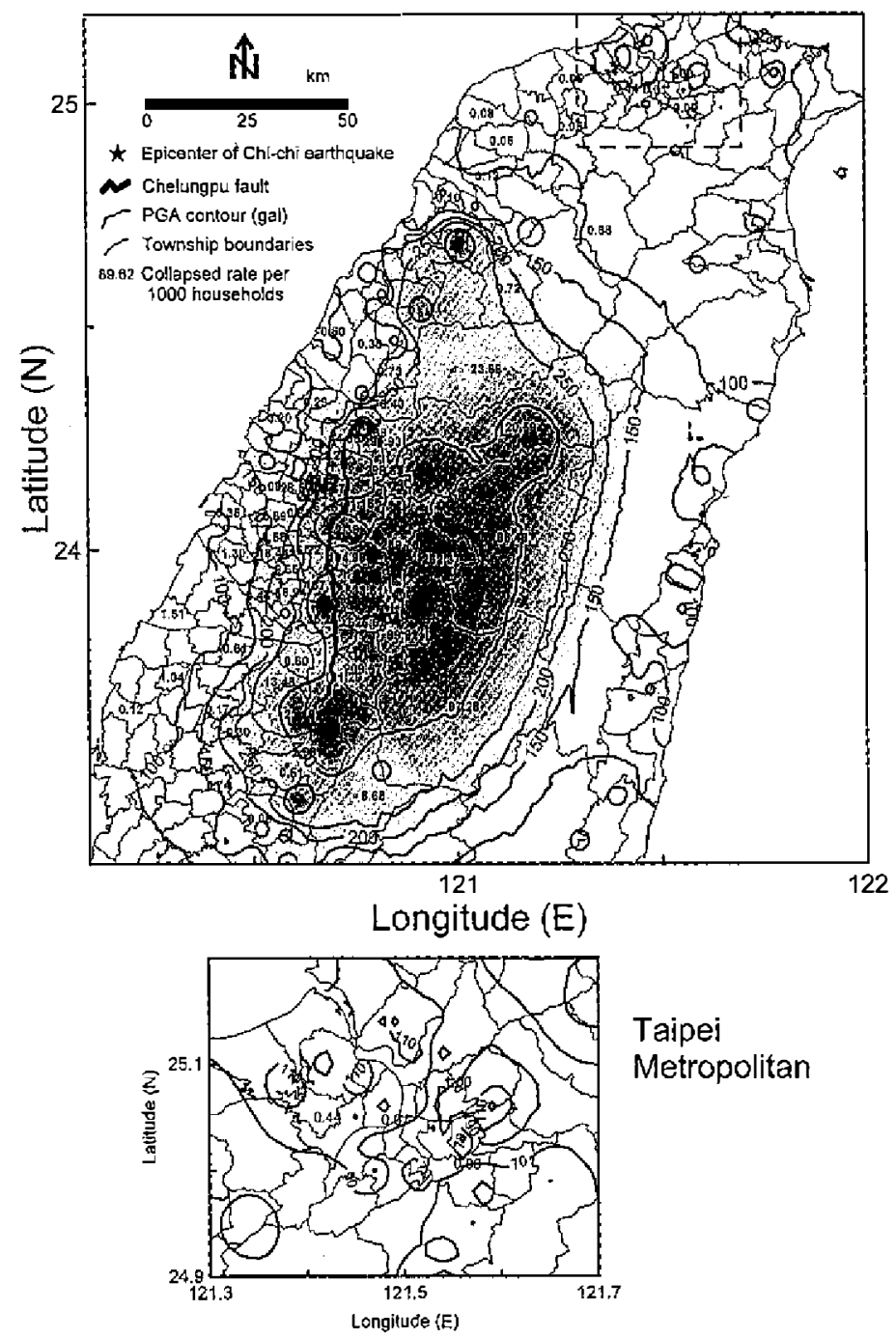

Taipei

Metropolitan

Fig. 3. The distribution of total household collapse rates and PGA values in individual townships in central and northern Taiwan.

by:

$$
\begin{aligned}
& \log _{10}(F r)=-12.572+4.282 * \log _{10}(P G A) \pm 0.657 \\
& \log _{10}(C t)=-10.118+4.146 * \log _{10}(P G A) \pm 0.508 \\
& \log _{10}(C p)=-9.941+4.061 * \log _{10}(P G A) \pm 0.501 \\
& \log _{10}(F r)=-9.360+4.315 * \log _{10}(P G V) \pm 0.341 \\
& \log _{10}(C t)=-8.452+4.825 * \log _{10}(P G V) \pm 0.483 \\
& \log _{10}(C p)=-8.007+4.452 * \log _{10}(P G V) \pm 0.541
\end{aligned}
$$



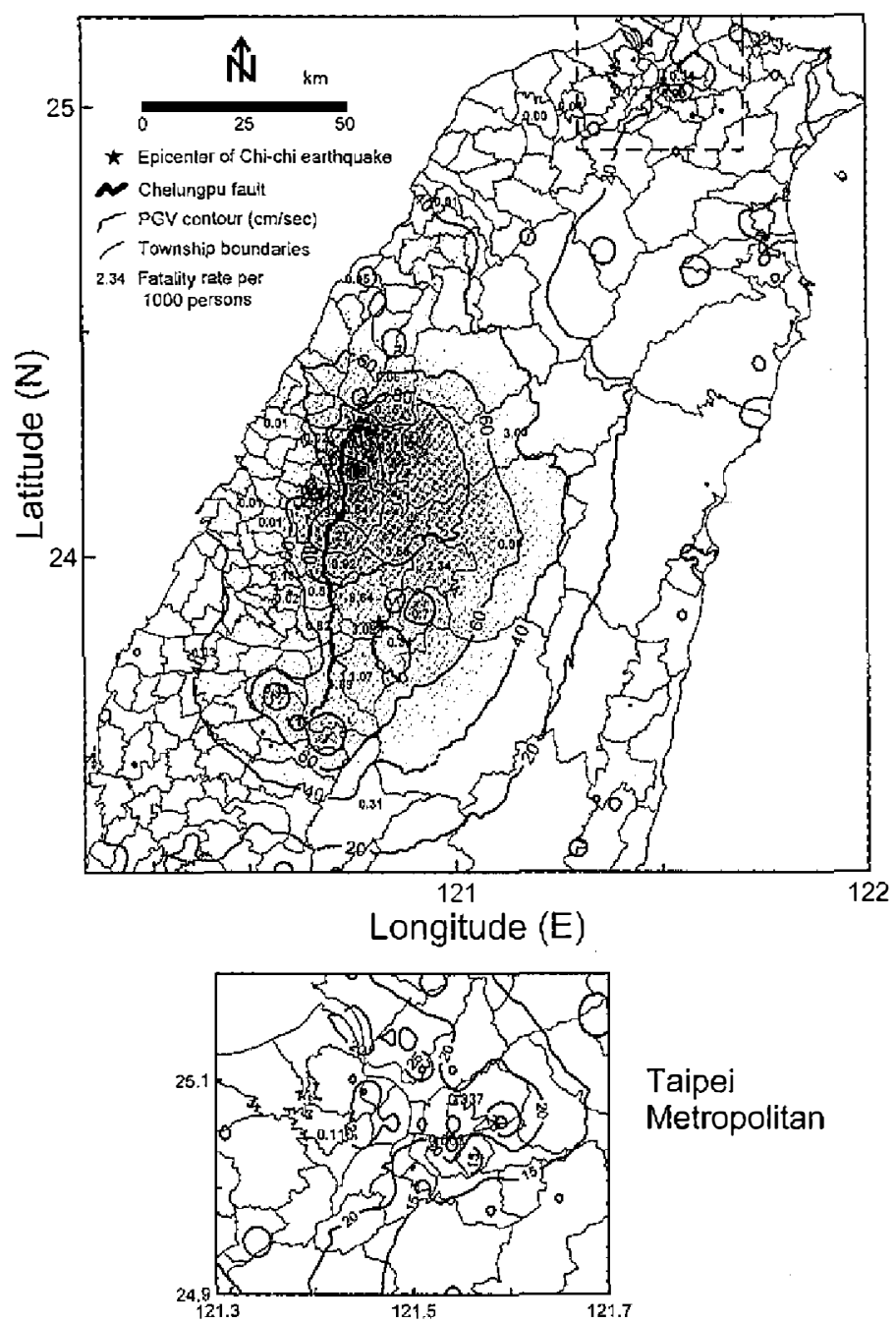

Taipej

Metropolitan

Fig. 4. The distribution of fatality rates and PGV values in individual townships in central and northern Taiwan.

where $\mathrm{Fr}, \mathrm{Ct}$, and $\mathrm{Cp}$ are rate percentages of the fatality, total and partial-collapsed households, respectively. PGA is the peak ground acceleration (gal). PGV is the peak ground velocity $(\mathrm{cm} /$ sec).

\section{DISCUSSIONS}

According to the relationships of PGA and PGV with damage rates (Table 1 and 2), no seismic damages occurred for PGA and PGV values lower than 50 gal and $10 \mathrm{~cm} / \mathrm{sec}$ during the Chi-Chi earthquake, and these two thresholds can be used for future seismic damage analysis.

Comparing the damage rate regression results from the PGA and PGV (equation 1; Figs 5 
Table 1. The distributions of fatality rate, total and partial household collapse rates within different PGA (Peak Ground Acceleration) ranges of the 1999 Chi-Chi earthquake.

\begin{tabular}{|c|c|c|c|}
\hline $\begin{array}{c}\text { PGA } \\
\text { Ranges } \\
\text { (gal) }\end{array}$ & $\begin{array}{c}\text { Fatality } \\
\text { Rate } \\
(\%)\end{array}$ & $\begin{array}{c}\text { Total } \\
\text { Household } \\
\text { Collapse Rate } \\
(\%)\end{array}$ & $\begin{array}{c}\text { Partial } \\
\text { Household } \\
\text { Collapse Rate } \\
(\%)\end{array}$ \\
\hline $50-75$ & $4.549 \mathrm{E}-06$ & $3.785 \mathrm{E}-03$ & $2.208 \mathrm{E}-03$ \\
$75-100$ & $7.637 \mathrm{E}-04$ & $4.816 \mathrm{E}-03$ & $4.492 \mathrm{E}-03$ \\
$100-125$ & $1.204 \mathrm{E}-04$ & $5.861 \mathrm{E}-03$ & $7.273 \mathrm{E}-03$ \\
$125-150$ & $1.678 \mathrm{E}-04$ & $1.943 \mathrm{E}-02$ & $1.910 \mathrm{E}-02$ \\
$150-175$ & $2.618 \mathrm{E}-04$ & $9.421 \mathrm{E}-02$ & 0.1212 \\
$175-200$ & $1.385 \mathrm{E}-04$ & 0.2459 & 0.4274 \\
$200-250$ & $2.303 \mathrm{E}-03$ & 2.350 & 4.236 \\
$250-300$ & $2.091 \mathrm{E}-02$ & 2.219 & 1.480 \\
$300-350$ & $8.912 \mathrm{E}-02$ & 4.337 & 3.545 \\
$350-400$ & 0.2092 & 9.976 & 5.436 \\
$400-500$ & $9.623 \mathrm{E}-02$ & 11.91 & 13.57 \\
$500-600$ & 0.3980 & 37.68 & 24.76 \\
$600-700$ & 0.1149 & 2.116 & 2.522 \\
$700-800$ & $7.734 \mathrm{E}-02$ & 48.32 & 30.03 \\
\hline
\end{tabular}

Table 2. The distributions of fatality rate, total and partial household collapse rates within different PGV (Peak Ground Velocity) ranges of the 1999 Chi-Chi earthquake.

\begin{tabular}{|c|c|c|c|}
\hline $\begin{array}{c}\text { PGV } \\
\text { Ranges } \\
(\mathrm{cm} / \mathrm{sec})\end{array}$ & $\begin{array}{c}\text { Fatality } \\
\text { Rate } \\
(\%)\end{array}$ & $\begin{array}{c}\text { Total } \\
\text { Household } \\
\text { Collapse Rate } \\
(\%)\end{array}$ & $\begin{array}{c}\text { Partial } \\
\text { Household } \\
\text { Collapse Rate } \\
(\%)\end{array}$ \\
\hline $10-20$ & $2.740 \mathrm{E}-05$ & $9.297 \mathrm{E}-04$ & $1.547 \mathrm{E}-03$ \\
$20-30$ & $7.876 \mathrm{E}-04$ & $8.507 \mathrm{E}-03$ & $6.515 \mathrm{E}-03$ \\
$30-40$ & $1.597 \mathrm{E}-03$ & $5.258 \mathrm{E}-02$ & $2.681 \mathrm{E}-02$ \\
$40-50$ & $9.164 \mathrm{E}-03$ & 0.8719 & 1.122 \\
$50-60$ & $3.995 \mathrm{E}-03$ & 0.5996 & 0.9571 \\
$60-70$ & $6.601 \mathrm{E}-02$ & 13.90 & 13.64 \\
$70-80$ & 0.2096 & 12.45 & 8.963 \\
$80-90$ & 0.2165 & 38.65 & 29.18 \\
$90-100$ & $8.005 \mathrm{E}-02$ & 7.255 & 8.926 \\
$100-125$ & 0.1519 & 16.53 & 8.423 \\
$125-150$ & 0.5929 & 29.09 & 23.69 \\
$150-175$ & 1.127 & 44.27 & 21.32 \\
\hline
\end{tabular}



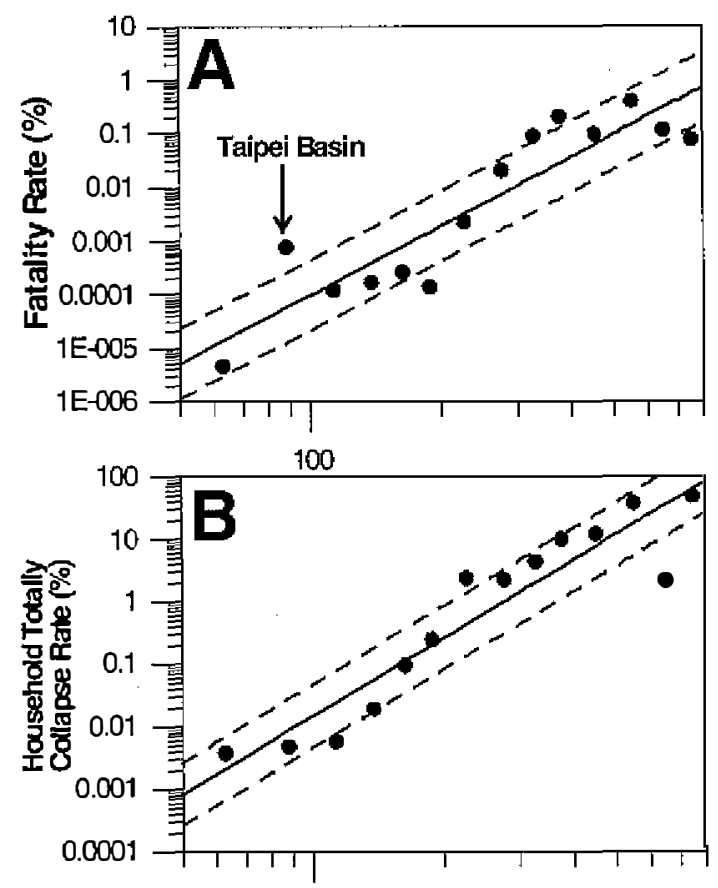

Fig. 5. (A) Relationship between fatality rate and PGA; (B) Relationship between total household collapse rate and PGA; (C) Relationship between partial household collapse rate and PGA.

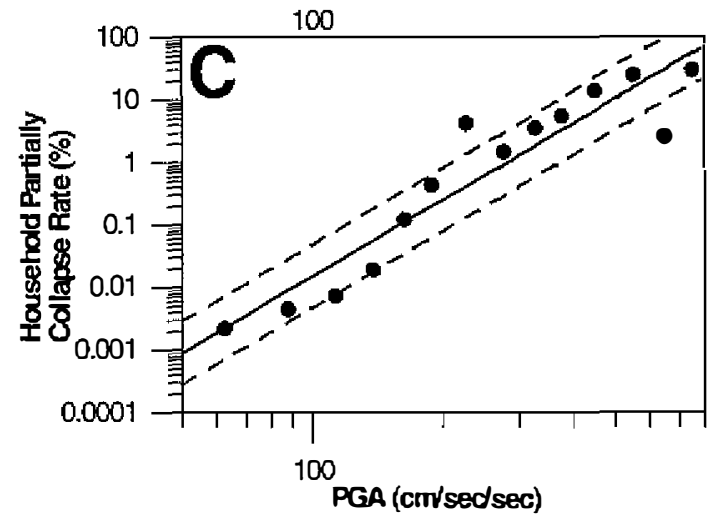

and 6), PGV regression with smaller standard deviations generally provide better results than PGA regression, and is especially true for fatality rate correlations. Although the standard deviation of $\mathrm{Cp}$ for $\mathrm{PGV}$ regression is larger than PGA, $\mathrm{Cp}$ is not as an important factor than $\mathrm{Ct}$ or $\mathrm{Fr}$ for damage assessment. Abnormal high fatality rates were recorded for PGA within the range of 75 to $100 \mathrm{gal}$, but the same response did not occur in household collapse rates (Fig. 5). This phenomenon can be explained by the collapsing of few high-rised buildings that caused high fatality in the Taipei basin. Therefore, even the Taipei basin has rather low PGA range, it experienced a relatively higher PGV values than other places. This abnormal phenomenon does not occur in the PGV regression (Fig. 6). The $\mathrm{Ct}$ and $\mathrm{Cp}$ for PGA at the range of 600 to 700 gal is abnonmally low (Fig. 5). This phenomenon may be explained by at least three events occurred at about Maioli and Chiayi region within one minute after the mainshock (Shin, 2000). These events caused high frequency acceleration signals due to mixing with the 

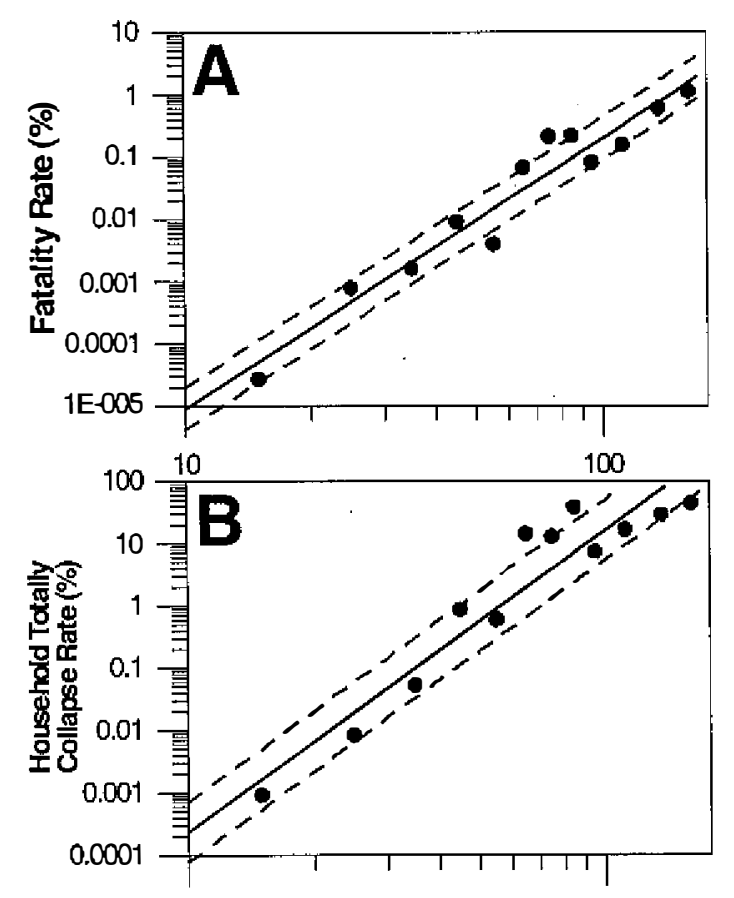

Fig. 6. (A) Relationship between fatality rate and PGV; (B) Relationship between total household collapse rate and PGV; (C) Relationship between partial household collapse rate and PGV.

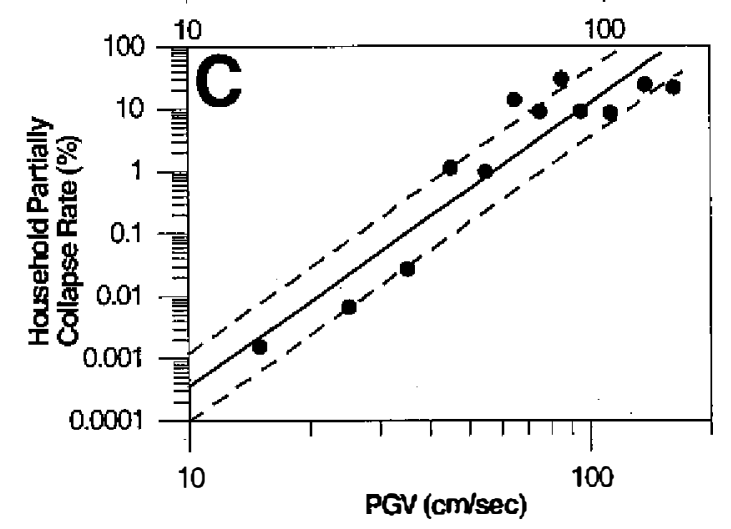

mainshock, but did not cause higher PGV and significant damages. Another important phenomenon during the Chi-Chi earthquake, observed is that dramatic increasing $(10 \%)$ of the household collapse rates occurred for PGV higher than $60 \mathrm{~cm} / \mathrm{sec}$.

Comparing the relationships between PGA, PGV and seismic damage rates determined in this study, we recommend that the PGV is a much better index for seismic damage assessment. It is also commonly observed that damageless small earthquakes can produce high PGA values near source regions, but high PGV values are only observed for large earthquakes. Figure 7 shows the predicted PGA and PGV curves for Mw 4.0, 5.0, 6.0 and 7.0 from Wu et al. (2001). According to the predicted PGV curves, earthquakes with $\mathrm{Mw}<5.0$ almost never produce PGV large than $10 \mathrm{~cm} / \mathrm{sec}$. However, earthquakes of $\mathrm{Mw}<5.0$ can produce PGA as large as 200 gal. Therefore, PGV is a more reliable index than PGA for damage assessment.

According to the predicted PGV curves, it also gives us information that Mw $<5.0$ earth- 

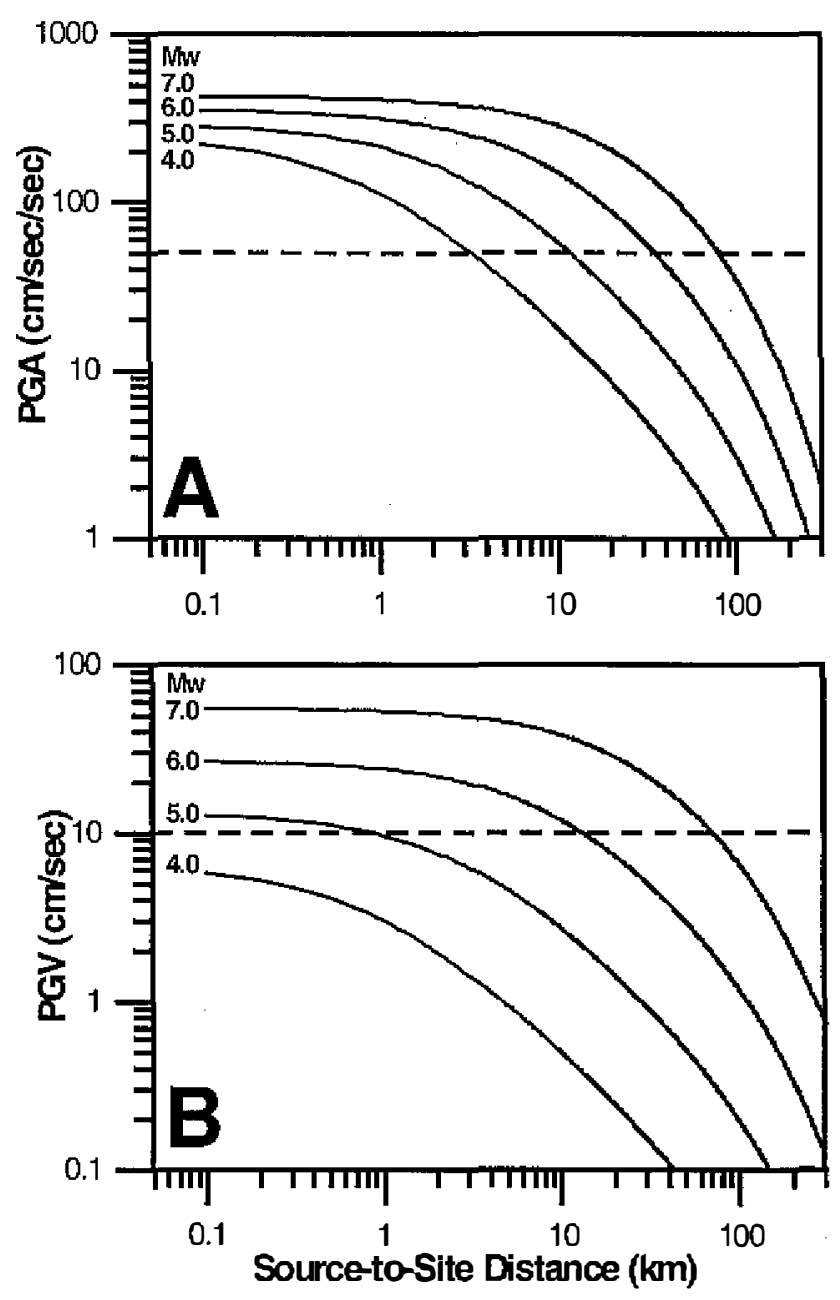

Fig. 7. (A) PGA attenuation curves for Mw 4.0, 5.0, 6.0 and 7.0 (solid lines), the dashed line shows PGA = 50 gal; (B) PGV attenuation curves for Mw 4. $0,5.0,6.0$ and 7.0 (solid lines), the dashed line shows PGV $=10 \mathrm{~cm} / \mathrm{sec}$.

quakes are generally undamaging in Taiwan. Thus, $\mathrm{Mw} 5.0$ can be defined as the lower limit for damaging earthquakes in Taiwan, where early warning work of earthquake should be focused.

\section{CONCLUSIONS}

In this study, we investigated the relationships between the damage rates (fatality rate, total and partial household collapse rates in individual townships) with PGA and PGV, and determined a total of six related relationships. According to our analysis, we conclude that PGV, rather than PGA, should be used as an index for the damage assessment as it gives a 
much better indication of damage potential.

The CWB rapid reporting system can provide a near real-time damage assessments by applying the existing database on buildings and population with distribution of PGV, which is critically useful for earthquake emergency response operations.

Acknowledgments The authors wish to thank Mr. Chen-Chun Chen for his kind help for data preparation of this study. The authors are deeply grateful to Drs. Y. B. Tsai, W. H. K. Lee, K. L. Wen, C. Wang and two anonymous reviewers for their valuable comments. This study was supported by the Central Weather Bureau and the National Science Council of the Republic of China under Grant No. NSC90-2625-Z-052-009 and NSC91-2116-M-052-001.

\section{REFERENCES}

Lee, W. H. K., T. C. Shin, K. W. Kuo, K. C. Chen, and C. F. Wu, 2001: CWB free-field strong-motion data from the 21 September Chi-Chi, Taiwan, earthquake. Bull. Seism. Soc. Am., 91, 1370-1376.

National Office of Statistics, 2000: Summary of important population statistics in 1999 (in Chinese). 921 Earthquake Post-Disaster Recovery Commission, http:/www.921erc.gov. tw.

National Office of Statistics, 2001: Important statistics about the Chi-Chi earthquake disaster (in Chinese). 921 Earthquake Post-Disaster Recovery Commission, http:/www.921erc. gov.tw.

Shin, T. C., 2000: Some seismological aspects of the 1999 Chi-Chi earthquake in Taiwan. TAO, 11, 555-566.

Teng, T. L., L. Wu, T. C. Shin, Y. B. Tsai, and W. H. K. Lee, 1997: One minute after: strongmotion map, effective epicenter, and effective magnitude. Bull. Seism. Soc. Am., 87, 1209-1219.

Tsai, Y. B., T. M. Yu, H. L. Chao, and C. P. Lee, 2001: Spatial distribution and age dependence of human-fatality rates from the Chi-Chi, Taiwan, Earthquake of 21 September 1999. Bull. Seism. Soc. Am., 91, 1298-1309.

United States Geological Survey, 1998: A plan for implementing a real-time seismic hazard warning system - A report to congress required by public law 105-47, 33p, March 27, 1998, USA.

Wu, Y. M., C. C. Chen, T. C. Shin, Y. B. Tsai, W. H. K. Lee, and T. L. Teng, 1997: Taiwan Rapid Earthquake Information Release System. Seism. Res. Lett, 68, 931-943.

Wu, Y. M., T. C. Shin, and Y. B. Tsai, 1998: Quick and reliable determination of magnitude for seismic early warning. Bull. Seism. Soc. Am., 88, 1254-1259.

Wu, Y. M., J. K. Chung, T. C. Shin, N. C. Hsiao, Y. B. Tsai, W. H. K. Lee, and T. L. Teng, 1999: Development of an integrated seismic early waming system in Taiwan. TAO, 10, 719-736.

Wu, Y. M., W. H. K. Lee, C. C. Chen, T. C. Shin, T. L. Teng, and Y. B. Tsai, 2000: Performance of the Taiwan Rapid Earthquake Information Release System (RTD) during the 1999 Chi-Chi (Taiwan) earthquake. Seism. Res. Let., 71, 328-333. 
Wu, Y. M., T. C. Shin, and C. H. Chang, 2001: Near realtime mapping of Peak Ground Acceleration and Peak Ground Velocity following a strong earthquake. Bull. Seism. Soc. Am., 91, 1218-1228.

Wu, Y. M. and T. L. Teng, 2002: A VSN approach to Earthquake Early Warning. Bull. Seism. Soc. Am., 92, 2008-2018.

Yu, S. B., L. C. Kuo, R. S. Punongbayan, and E. G. Ramos, 1999: GPS observation of crustal deformation in the Taiwan-Luzon region. Geophys. Res. Lett., 26, 923-926. 